\title{
Frequency of Human Immunodeficiency Virus in Patients Admitted with Acute Stroke
}

Rahmat Ali ${ }^{1}$, Muhammad Inam Khan ${ }^{2}$, Muhammad Omer Sultan ${ }^{2}$, Umar Farooque ${ }^{3}$, Syed Adeel Hassan 4, 5 , Fahham Asghar ${ }^{3}$, Omer Cheema ${ }^{5}$, Sundas Karimi ${ }^{6}$, Choudhary Ahmed Hasan ${ }^{5}$, FNU Farukhuddin ${ }^{7}$

1. Internal Medicine, United Medical and Dental College, Karachi, PAK 2. Internal Medicine, Jinnah Postgraduate Medical Center, Karachi, PAK 3. Neurology, Dow Medical College, Dow University of Health Sciences, Karachi, PAK 4. Neurology, Dow University of Health Sciences, Karachi, PAK 5. Internal Medicine, Dow University of Health Sciences, Karachi, PAK 6. General Surgery, Combined Military Hospital, Karachi, PAK 7. Neurology, University Hospital Cleveland Medical Center, Cleveland, USA

Corresponding author: Umar Farooque, umarfarooque65@gmail.com

\section{Abstract \\ Introduction}

Stroke is a leading cause of chronic disability and death in both developing and developed countries. A significant proportion of stroke patients are human immunodeficiency virus (HIV) positive. About half of the HIV patients experience some sort of neurological deficit in their lifetimes. The exact reason for the occurrence of stroke in HIV infected patients is poorly understood. The purpose of our study is to determine the frequency of HIV among patients admitted with acute stroke.

\section{Materials and methods}

This cross-sectional study is conducted at a major metropolitan hospital in Karachi for six months. A total of 130 patients of stroke between the ages of 30 and 70 years of either gender were included in this study. A complete history was taken and a physical examination was performed. Each patient underwent a battery of tests that included HIV serology, lipid profile, electrocardiography (ECG), chest X-ray (posteroanterior (PA) view), and computed tomography (CT) scan of the brain. Carotid Doppler ultrasonography to assess carotid artery stenosis was also ordered. The means and standard deviations of age and cluster of differentiation 4 (CD4) cell count were calculated. The frequencies and proportions of gender, diabetes mellitus (DM), hypertension (HTN), smoking, obesity, dyslipidemia, carotid artery stenosis, and HIV status were calculated. Stratification was done by applying the chi-square test and assuming $p$-value $\leqslant 0.05$ as significant. This helped analyze the association of age, gender, DM, HTN, smoking, obesity, dyslipidemia, and carotid artery stenosis to the frequency of HIV.

\section{Results}

The mean age of the study population was $55.54 \pm 11.166$ years. There were 39 (30\%) patients $<50$ years of age while $91(70 \%)$ patients were $\geqslant 50$ years of age. Gender distribution showed that $86(66.15 \%)$ patients were male, and 44 (33.85\%) patients were female. Furthermore, 71 (54.62\%) patients were hypertensive, 53 (40.77\%) were diabetic, 62 (47.69\%) were smokers, 49 (37.69\%) were obese, 52 (40\%) had dyslipidemia, and 77 (59.23\%) had carotid artery stenosis. The frequency of HIV was noted at 24 (18.46\%). The mean CD4 count was estimated at $241 \pm 103.295 \mathrm{cells} / \mathrm{mm}^{3}$. Stratification showed a significant relationship between the frequency of HIV with only gender $(\mathrm{p}=0.01)$ and dyslipidemia $(\mathrm{p}=0.037)$.

Ali et al. This is an open access article distributed under the terms of the Creative Commons Attribution License CC-BY 4.0., which permits unrestricted use, distribution, and reproduction in any medium, provided the original author and source are credited.

\section{Conclusion}

HIV infection in patients with stroke is not uncommon. Patients who are male, younger in age, have dyslipidemia, belong to a low socioeconomic class, or have a bad sexual history are more likely to have HIV as an underlying cause of stroke. The exact pathogenesis of such a stroke and the role of antiretroviral therapy in the prevention and treatment of this group of stroke are not completely understood and need further analysis.

Categories: Internal Medicine, Neurology, HIV/AIDS

Keywords: seropositive, stroke, cd4 count, frequency, dyslipidemia, male, hiv

\section{Introduction}

Stroke is an important cause of chronic physical disability and mortality. The risk of its occurrence increases with age. Overall, the five-year risk of recurrent stroke is estimated at 20\% [1]. According to the World Health Organization (WHO), it will continue to be the second leading cause of death in 2020.

A recent study estimated that the prevalence of stroke and/or transient ischemic attack is $21.8 \%$ in Karachi, 
There are many risk factors of stroke, and the human immunodeficiency virus (HIV) infection adds to that list [4-5]. According to the study conducted by Mlay et al., the prevalence of HIV is $20.9 \%$ among stroke patients [6]. About 50\% of HIV patients present with cerebral infarction or transient neurological deficits in their lifetimes [7]. The exact underlying mechanism remains unclear. The hypothesized pathogenesis includes the formation of a cardiac embolus due to the development of HIV-related dilated cardiomyopathy. Furthermore, it is thought that the HIV-associated elevated systemic inflammation and the toxic effects of viral antigen leading to vascular damage and atherosclerosis can be the underlying mechanisms [8-11]. According to another study, the carotid intima-media thickness in HIV patients was more than that in nonHIV patients of the same age. The thickness advanced more quickly than earlier stated rates in non-HIV cohorts and was related to the vascular risk factors and a low cluster of differentiation 4 (CD4) count of $\leqslant 200$ cells $/ \mathrm{mm}^{3}$. This proposes that immunodeficiency and traditional vascular risk factors can predispose to atherosclerosis [12].

The incidence of HIV and acquired immunodeficiency syndrome (AIDS) is increasing in Pakistan. Therefore, the present study is designed to determine the frequency of HIV in patients admitted with acute stroke.

\section{Materials And Methods \\ Study design and sampling}

This cross-sectional study took place at Jinnah Postgraduate Medical Center, Karachi, from March 20, 2019, to September 20, 2019 (six months). The non-probability consecutive sampling technique was used. The sample size was calculated by taking the prevalence of HIV in stroke patients as $20.9 \%$, confidence interval at $95 \%$, and margin of error at $7 \%$. The input of the aforementioned information in Epi Info 7 (Centers for Disease Control and Prevention, Atlanta, Georgia) estimated the sample size of 130 patients. Inclusion criteria were age 30-70 years, either gender, and a confirmed diagnosis of stroke. Exclusion criteria included a space-occupying lesion on a computed tomography (CT) scan of the brain, signs of meningeal irritation, such as neck stiffness or a positive Kernig test, and a history of other serious comorbidities such as heart failure (ejection fraction (EF) 40 on echocardiography), chronic obstructive pulmonary disease (forced expiratory volume in one second $(\mathrm{FEV} 1)<70 \%$ predicted on pulmonary function testing (PFT)), or malignancy (with documented proof).

\section{Data collection}

Stroke patients meeting the inclusion criteria were selected for the study. All participants were educated about the study before inclusion and informed consent was taken. A detailed history and thorough physical examination were carried out in all patients. Each patient underwent a list of investigations, including HIV serology, lipid profile, electrocardiography (ECG), chest X-ray (posteroanterior (PA) view), and CT scan of the brain. During hospitalization, the patients were subjected to carotid Doppler ultrasonography to assess the degree of carotid artery stenosis. Patients with HIV positive tests were recorded in the proforma by the researcher. Patients were provided with routine medical care during the hospitalization.

\section{Data analysis}

Data were entered and analyzed on SPSS version 19 (SPSS Statistics, Chicago, IL). Mean and standard deviation was calculated for continuous variables such as age and CD4 cell count. Frequency and percentage were calculated for categorical variables such as gender, diabetes mellitus (DM), hypertension (HTN), smoking, obesity, dyslipidemia, carotid artery stenosis, and the patient outcome variable, i.e. the frequency of HIV. Stratification of age, gender, DM, HTN, smoking, obesity, dyslipidemia, and carotid artery stenosis was done, the chi-square test was applied, and $p$-value $\leqslant 0.05$ was considered significant.

\section{Results}

The mean \pm standard deviation age of the patients was $55.54 \pm 11.166$ years, as shown in Table 1 .

\begin{tabular}{|c|c|c|c|c|}
\hline & Minimum & Maximum & Mean & Standard Deviation \\
\hline Age & 39 & 70 & 55.54 & 11.166 \\
\hline
\end{tabular}

TABLE 1: Analysis of age

There were 39 (30\%) patients $<50$ years of age and 91 (70\%) patients $\geqslant 50$ years of age, as shown in Figure 1 . 


\section{Cureus}

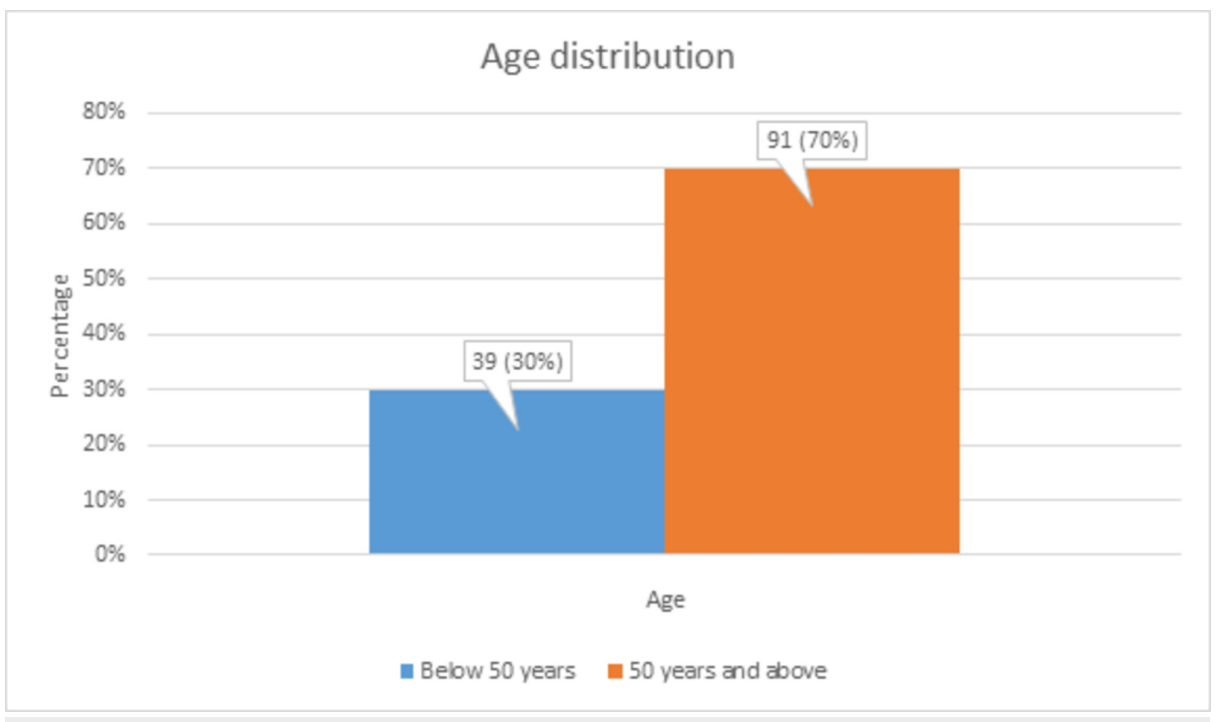

\section{FIGURE 1: Age distribution}

There were 86 (66.15\%) male patients and 44 (33.85\%) female patients, as shown in Figure 2.

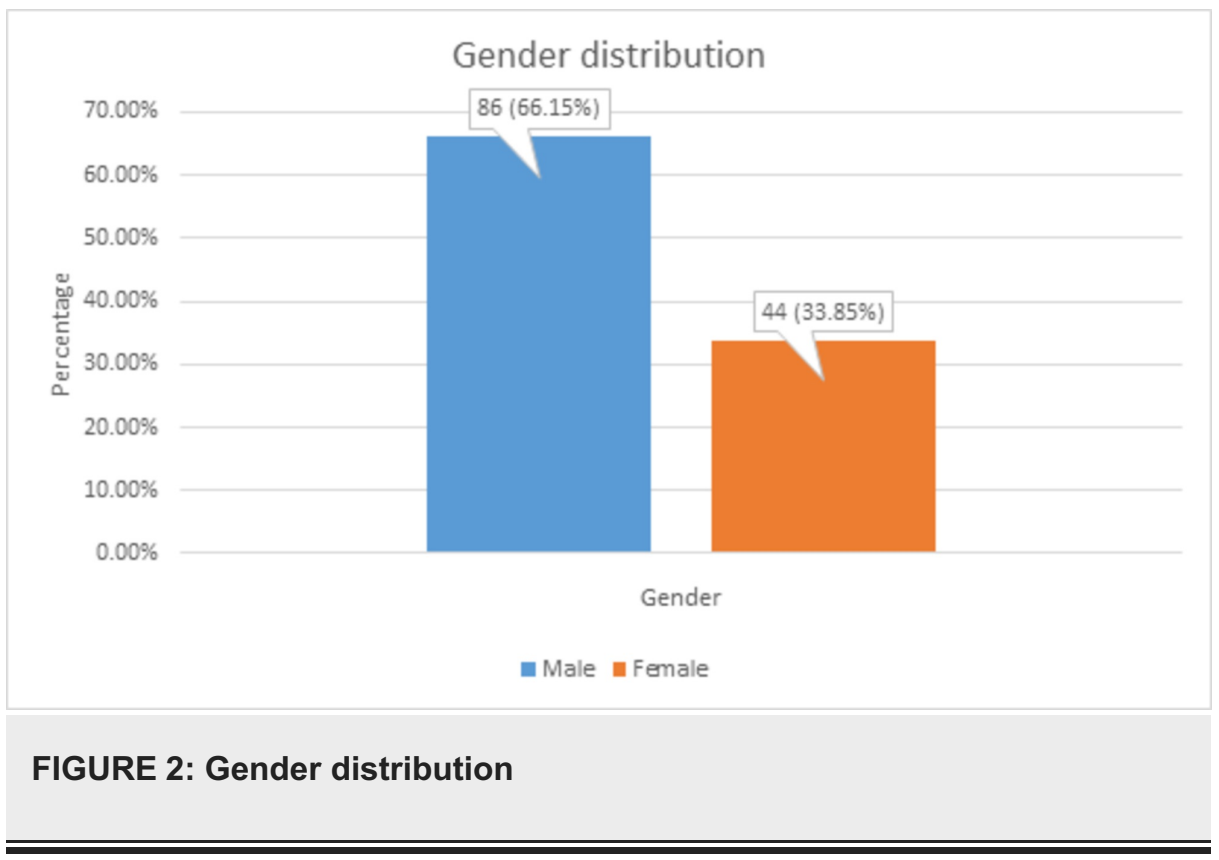

There were 71 (54.62\%) patients with HTN, 53 (40.77\%) patients with DM, 62 (47.69\%) patients with positive smoking status, 49 (37.69\%) patients with obesity, 52 (40\%) patients with dyslipidemia, and 77 (59.23\%) patients with carotid artery stenosis. These frequencies of vascular risk factors of stroke are shown in Figure 3. 


\section{Cureus}

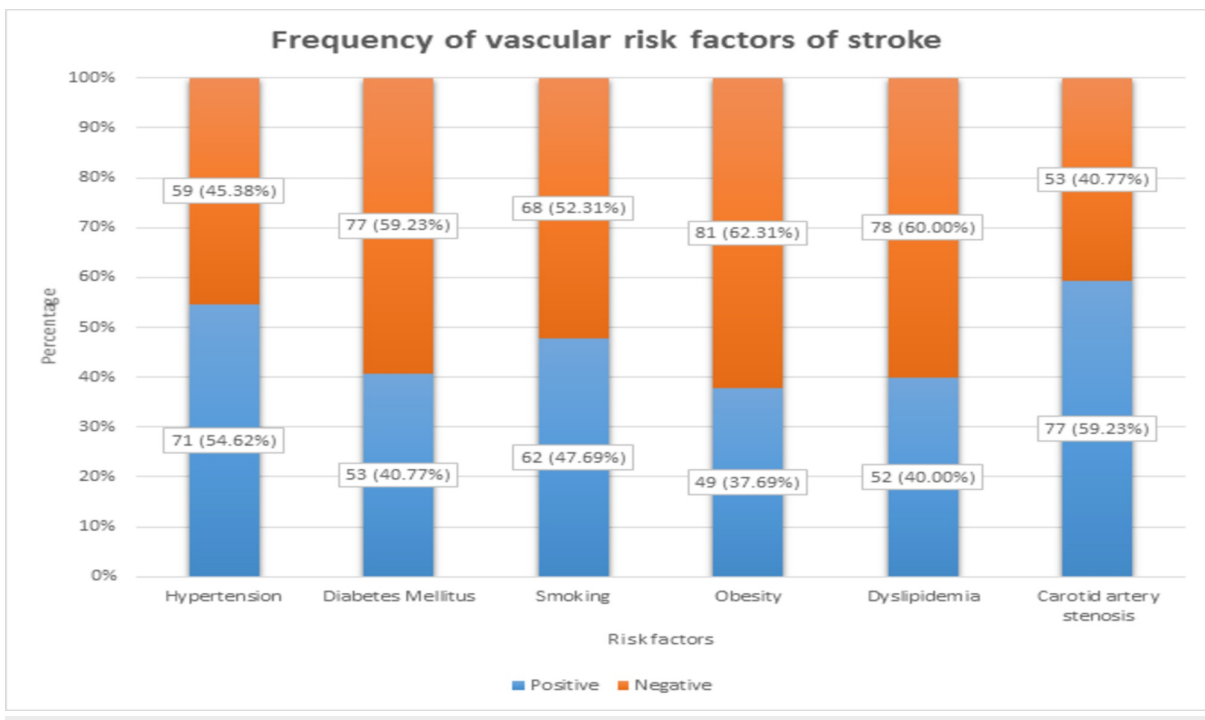

FIGURE 3: Frequency of the vascular risk factors of stroke

On analysis of the frequency of outcome variable, 24 (18.46\%) patients were HIV positive, as shown in Figure 4 . The mean \pm standard deviation CD4 count was $241 \pm 103.2955$ cells $/ \mathrm{mm}^{3}$.

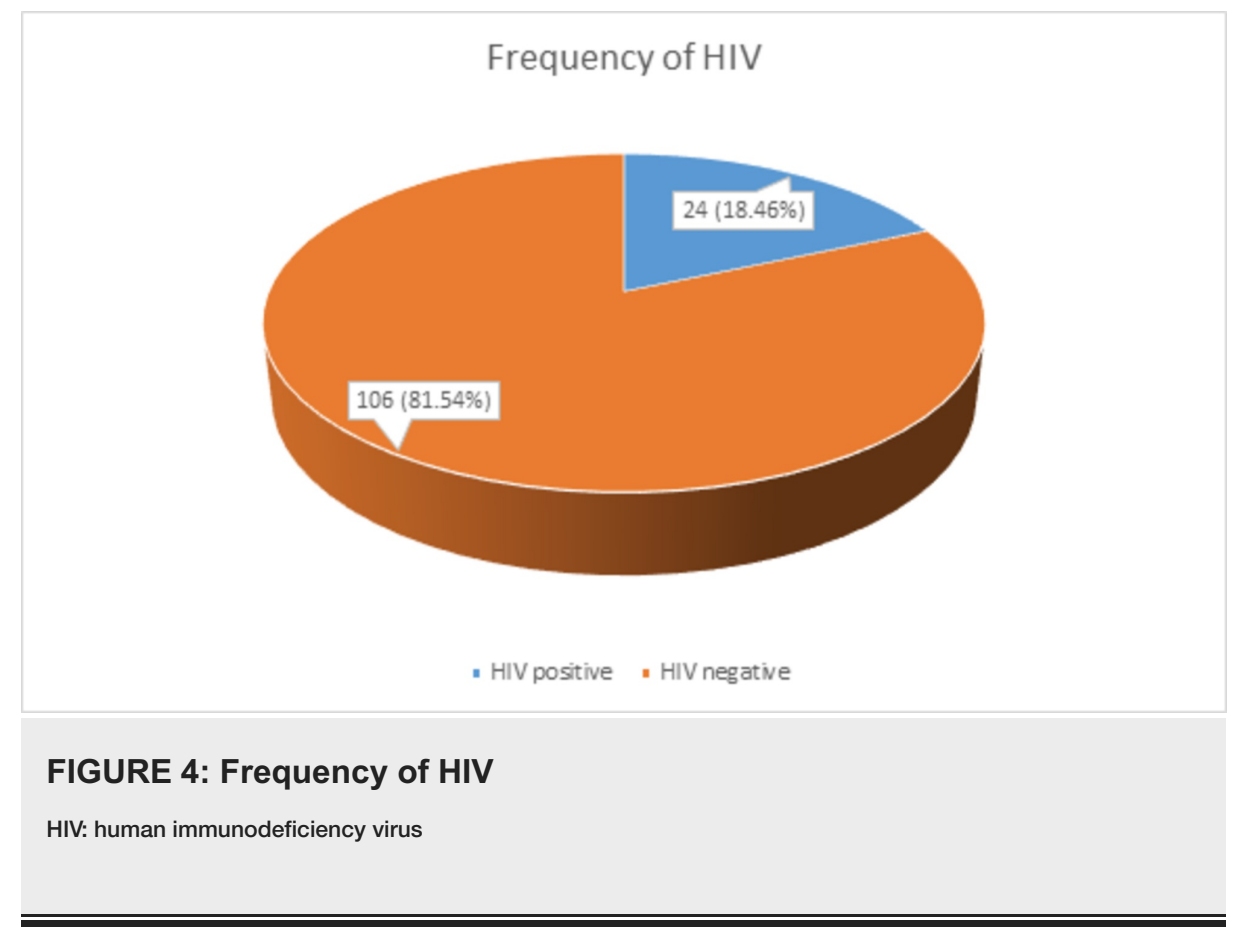

Stratification of age, gender, HTN, DM, smoking, obesity, dyslipidemia, and carotid artery stenosis with HIV prevalence indicated a statistically significant relationship only in gender $(\mathrm{p}=0.01)$ and dyslipidemia $(\mathrm{p}=0.037)$, as shown in Table 2 . 


\begin{tabular}{|c|c|c|c|c|}
\hline \multirow{2}{*}{ Parameters } & & \multicolumn{2}{|c|}{ HIV positive } & \multirow{2}{*}{ p-value } \\
\hline & & Yes & No & \\
\hline \multirow{2}{*}{ Age } & Below 50 years & 11 & 28 & \multirow{2}{*}{0.061} \\
\hline & 50 years and above & 13 & 78 & \\
\hline \multirow{2}{*}{ Gender } & Male & 21 & 65 & \multirow{2}{*}{0.010} \\
\hline & Female & 03 & 41 & \\
\hline \multirow{2}{*}{ Hypertension } & Yes & 13 & 58 & \multirow[b]{2}{*}{0.569} \\
\hline & No & 11 & 48 & \\
\hline \multirow{2}{*}{ Diabetes Mellitus } & Yes & 12 & 41 & \multirow{2}{*}{0.214} \\
\hline & No & 12 & 65 & \\
\hline \multirow{2}{*}{ Smoking } & Yes & 11 & 51 & \multirow{2}{*}{0.211} \\
\hline & No & 13 & 55 & \\
\hline \multirow{2}{*}{ Obesity } & Yes & 11 & 38 & \multirow{2}{*}{0.247} \\
\hline & No & 13 & 68 & \\
\hline \multirow{2}{*}{ Dyslipidemia } & Yes & 14 & 38 & \multirow{2}{*}{0.037} \\
\hline & No & 10 & 68 & \\
\hline \multirow{2}{*}{ Carotid artery stenosis } & Yes & 11 & 66 & \multirow{2}{*}{0.106} \\
\hline & No & 13 & 40 & \\
\hline
\end{tabular}

TABLE 2: Stratification of demographic variables and vascular risk factors of stroke with HIV prevalence

HIV: human immunodeficiency virus

\section{Discussion}

This study estimates the frequency of HIV infection among patients with acute stroke at $18.5 \%$, which has a statistically significant relationship with male gender and dyslipidemia. Recognition of HIV as a cause of stroke may lead to the early initiation of antiretroviral therapy. Hence, the results of this study warrant better medical management of this group of stroke patients.

In the past decade, stroke incidence has raised by $100 \%$ in developing countries [13]. This staggering rise is mainly because of the increased incidence of vascular risk factors, increased proportions of the old population, and infections such as HIV [14]. As HIV infection is most prevalent in developing countries, the chance of one patient having both stroke and HIV coincidentally is high. Although HIV infection is a risk factor for stroke, its treatment may further increase the risk because it makes HIV patients able to live longer and get continuously exposed to a suppressed HIV infection and because of its possible role in vascular damage [15-17].

The most important risk factors for stroke include increasing age and male gender [18-19]. On the contrary, HIV-positive stroke patients are usually younger than non-HIV stroke patients. This is because younger patients are more predisposed to HIV infection, or it indicates that HIV can cause stroke independent of other vascular risk factors. The median age of HIV-positive stroke patients in developed countries like the USA is between 42 and 48 years. In developing countries like South Africa and Malawi, the median age is between 33 and 39 years [20-22]. The reason behind this variation can be the use of antiretroviral therapy in developed countries, which delays the onset of stroke in HIV patients, leading to increased median age in these countries.

HTN increases the risk of a stroke three times more than that in normotensive individuals [13]. HTN was noted in 71 (54.62\%) patients in our study. Therefore, like other South Asian and Western studies, HTN was common in our study [23-24]. Patients with DM have a four-fold increased risk of stroke [5]. When compared, the frequency of DM was found to be higher in our population $(18 \%-42.5 \%)$ than in the Western 
population (10\%-26\%) [25]. Smoking increases the risk of stroke by 1.5 to 2.9 times more than that in nonsmokers. This risk reverses back to normal after five to 10 years of smoking cessation [13]. The pattern of smoking/tobacco chewing is similar locally and in the West [26]. Dyslipidemia is undoubtedly related to the severity of carotid atherosclerosis. Despite this fact, the association between serum cholesterol and stroke risk remains a mystery [24]. Locally, dyslipidemia is estimated to have a frequency of $15.4 \%-32 \%$, whereas its frequency is estimated at $22 \%-29 \%$ in the West [26].

In a clinical series, a large proportion (4\%-34\%) of HIV patients had cerebral ischemic lesions at autopsy. However, only $1 \%-5 \%$ of patients with HIV developed stroke when alive. Therefore, the association of cerebral autopsy lesions with clinical manifestations before death was weak [27-28]. In the last nine years, the admission of HIV-positive stroke patients has increased by $43 \%$ in the US [29]. Despite the apparent association of HIV and stroke, little attention is being paid to find out the degree of stroke risk in HIV patients and its pathogenesis [30].

\section{Conclusions}

HIV is fairly frequent among stroke patients, especially those who are young, males, have dyslipidemia, belong to a low social-economic class, or have a sexual history indicative of a high risk of sexually transmitted diseases. Therefore, such patients should be tested for HIV. The pathogenesis of stroke in HIV patients and the role of antiretroviral therapy in the treatment and prevention of stroke due to HIV is still controversial. Therefore, further studies are needed so that a better approach can be devised to prevent and treat stroke in HIV patients.

\section{Additional Information \\ Disclosures}

Human subjects: Consent was obtained by all participants in this study. Animal subjects: All authors have confirmed that this study did not involve animal subjects or tissue. Conflicts of interest: In compliance with the ICMJE uniform disclosure form, all authors declare the following: Payment/services info: All authors have declared that no financial support was received from any organization for the submitted work. Financial relationships: All authors have declared that they have no financial relationships at present or within the previous three years with any organizations that might have an interest in the submitted work. Other relationships: All authors have declared that there are no other relationships or activities that could appear to have influenced the submitted work.

\section{References}

1. Hjalmarsson C, Bokemark L, Manhem K, Mehlig K, Andersson B: The effect of statins on acute and longterm outcome after ischemic stroke in the elderly. Am J Geriatr Pharmacother. 2012, 10:313-322. 10.1016/j.amjopharm.2012.09.001

2. Alam I, Haider I, Wahab F, Khan W, Taqweem MA, Nowsherwan: Risk factors stratification in 100 patients of acute stroke. J Postgrad Med Inst. 2004, 18:583-591.

3. Kamal AK, Itrat A, Murtaza M, et al.: The burden of stroke and transient ischemic attack in Pakistan: a community-based prevalence study. BMC Neurol. 2009, 9:58. 10.1186/1471-2377-9-58

4. Marcus JL, Leyden WA, Chao CR, et al.: HIV infection and incidence of ischemic stroke. AIDS. 2014, 28:1911-1919. 10.1097/QAD.0000000000000352

5. Silverberg MJ, Leyden WA, Xu L, et al.: Immunodeficiency and risk of myocardial infarction among HIVpositive individuals with access to care. J Acquir Immune Defic Syndr. 2014, 65:160-166. 10.1097/OAI.0000000000000009

6. Mlay M, Bakari M: The prevalence of HIV among patients admitted with stroke at the Muhimbili National Hospital, Dar es Salaam, Tanzania. Tanzan J Health Res. 2010, 12:105-113. 10.4314/thrb.v12i2.56397

7. Valcour V, Sithinamsuwan P, Letendre S, Ances B: Pathogenesis of HIV in the central nervous system. Curr HIV/AIDS Rep. 2011, 8:54-61. 10.1007/s11904-010-0070-4

8. Kranick SM, Nath A: Neurologic complications of HIV-1 infection and its treatment in the era of antiretroviral therapy. Continuum (Minneap Minn). 2012, 18:1319-1337.

9. Kumwenda JJ, Mateyu G, Kampondeni S, van Dam AP, van Lieshout L, Zijlstra EE: Differential diagnosis of stroke in a setting of high HIV prevalence in Blantyre, Malawi. Malawi Med J. 2005, 17:107-111. 10.4314/mmj.v17i4.10891

10. Stöllberger C, Finsterer J: Role of infectious and immune factors in coronary and cerebrovascular arteriosclerosis. Clin Diagn Lab Immunol. 2002, 9:207-215. 10.1128/CDLI.9.2.207-215.2002

11. Bogorodskaya M, Chow FC, Triant VA: Stroke in HIV. Can J Cardiol. 2019, 35:280-287. 10.1016/j.cjca.2018.11.032

12. Hsue PY, Lo JC, Franklin A, Bolger AF, Martin JN, Deeks SG, Waters DD: Progression of atherosclerosis as assessed by carotid intima-media thickness in patients with HIV infection. Circulation. 2004, 109:16031608. 10.1161/01.CIR.0000124480.32233.8A

13. Feigin VL, Lawes CM, Bennett DA, Barker-Collo SL, Parag V: Worldwide stroke incidence and early case fatality reported in 56 population-based studies: a systematic review. Lancet Neurol. 2009, 8:355-369. 10.1016/S1474-4422(09)70025-0

14. Walker R, Whiting D, Unwin N, et al.: Stroke incidence in rural and urban Tanzania: a prospective, community-based study. Lancet Neurol. 2010, 9:786-792. 10.1016/S1474-4422(10)70144-7

15. Quinn TC: Global burden of the HIV pandemic . Lancet. 1996, 348:99-106. 10.1016/s0140-6736(96)01029-X 
16. Sen S, Rabinstein AA, Elkind MS, Powers WJ: Recent developments regarding human immunodeficiency virus infection and stroke. Cerebrovasc Dis. 2012, 33:209-218. 10.1159/000335300

17. Feinstein MJ, Hsue PY, Benjamin LA, et al.: Characteristics, prevention, and management of cardiovascular disease in people living with HIV: a scientific statement from the American Heart Association. Circulation. 2019, 140:98-124. 10.1161/CIR.0000000000000695

18. Sacco RL: Risk factors and outcomes for ischemic stroke. Neurology. 1995, 45:S10-S14.

19. Kaul S, Venketswamy P, Meena AK, Sahay R, Murthy JM: Frequency, clinical features and risk factors of lacunar infarction (data from a stroke registry in South India). Neurol India. 2000, 48:116-119.

20. Ortiz G, Koch S, Romano JG, Forteza AM, Rabinstein AA: Mechanisms of ischemic stroke in HIV-infected patients. Neurology. 2007, 68:1257-1261. 10.1212/01.wnl.0000259515.45579.1e

21. Tipping B, de Villiers L, Wainwright H, Candy S, Bryer A: Stroke in patients with human immunodeficiency virus infection. J Neurol Neurosurg Psychiatry. 2007, 78:1320-1324. 10.1136/jnnp.2007.116103

22. Heikinheimo T, Chimbayo D, Kumwenda JJ, Kampondeni S, Allain TJ: Stroke outcomes in Malawi, a country with high prevalence of HIV: a prospective follow-up study. PLoS One. 2012, 7:e33765. Accessed: January 2, 2020: https://journals.plos.org/plosone/article?id=10.1371/journal.pone.0033765. 10.1371/journal.pone.0033765

23. Vohra EA, Ahmed WU, Ali M: Aetiology and prognostic factors of patients admitted for stroke. J Pak Med Assoc. 2000, 50:234-236.

24. Sandercock PA, Warlow CP, Jones LN, Starkey IR: Predisposing factors for cerebral infarction: the Oxfordshire community stroke project. BMJ. 1989, 298:75. 10.1136/bmj.298.6666.75

25. Javed MA, Ahmed M, Sial MSH, Naheed T: Risk factors in stroke. Pakistan J Neurol. 1998, 4:55-58.

26. Basharat RA, Yousuf M, Iqbal J, Khan MM: Frequency of known risk factors for stroke in poor patients admitted to Lahore General Hospital in 2000. Pak J Med Sci. 2002, 18:280-283.

27. Kieburtz KD, Eskin TA, Ketonen L, Tuite MJ: Opportunistic cerebral vasculopathy and stroke in patients with the acquired immunodeficiency syndrome. Arch Neurol. 1993, 50:430-432.

10.1001/archneur.1993.00540040082019

28. Connor MD, Lammie GA, Bell JE, Warlow CP, Simmonds P, Brettle RD: Cerebral infarction in adult AIDS patients: observations from the Edinburgh HIV autopsy cohort. Stroke. 2000, 31:2117-2126. 10.1161/01.str.31.9.2117

29. Ovbiagele B, Nath A: Increasing incidence of ischemic stroke in patients with HIV infection . Neurology. 2011, 76:444-450. 10.1212/WNL.0b013e31820a0cfc

30. Berger JR: AIDS and stroke risk. Lancet Neurol. 2004, 3:206-207. 10.1016/S1474-4422(04)00704-5 